education networks and programs. The statements are being revised and edited and will be published in the December 1997 issue of $P S$.

In their discussion, meeting participants discussed strategies by which political scientists could use their research to help develop stronger pre-college civics education programs and centered on the need for teacher training at the pre-college level. Participants recommended that APSA and the regional and state political science associations develop professional education programs for teachers and assist in developing quality instructional materials in civics education.

The Task Force plans to establish working groups on pre-college education, experiential education, and electronic communication and technologies in civic education. Information and appropriate collaboration with cognate professional organizations and the special projects on civil society and education reform are other Task Force activities.

\section{Congresswoman Fowler Defends the NEH}

\section{John Hammer, National \\ Humanities Alliance}

Representative Tillie Fowler (RFL) has represented Florida's 4th District since 1993. Now in her third term, she has emerged as a key

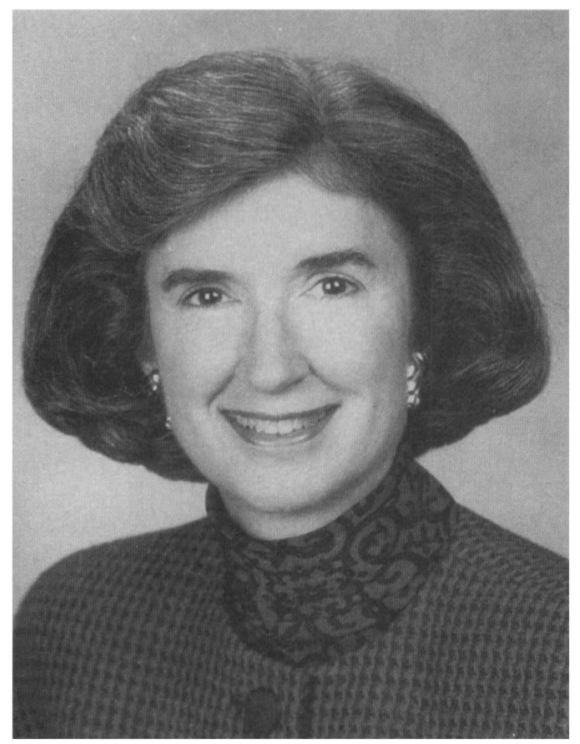

Tillie Fowler player in the ongoing fight to retain the National Endowment for the Humanities (NEH).

In recent months, she initiated and co-sponsored with Representative John Spratt (D-SC) a letter signed by 155 members of the House to Appropriations Subcommittee chair Representative Ralph Regula $(\mathrm{R}-\mathrm{OH})$ with a concluding paragraph reading: "Mr. Chairman, we realize that you face many difficult funding decisions, but we hope that you will consider the many community benefits of the humanities and provide for an appropriate level of continued funding. Federal funding is particularly appropriate because it leverages private dollars"-an ingeniously vague wording that permitted many more members to sign on than would have been the case with a direct call for increased funding or a dollar amount.

Also, in response to Representative Steve Chabot's (R-OH) proposed amendment that would have eliminated NEH at the end of September 1997, she authored a "Dear Colleague" letter headed " 10 Reasons to Vote No on the Chabot Amendment and Support the $\mathrm{Hu}-$ manities." The letter was circulated hours before the decisive defeat of the Chabot Amendment by 96 yea, 328 nay. In addition to authoring the letter, Representative Fowler spoke strongly and effectively on the floor of the House and in other venues about the value of the NEH.

Rep. Fowler, who earned a B.A. in political science in 1964 and a J.D. in 1967 from Emory University, arrived in Congress with previous experience as a Hill staffer and an aide in the Nixon White House. Of considerable import for her role as defender of the NEH was her 1989-91 experience as chair of the Florida Humanities Council. Her emergence as a champion of the $\mathrm{NEH}$ as older champions left Congress came at a most propitious time for the agency as it had been swept up in the ongoing imbroglio surrounding the National Endowment for the Arts.

John Hammer is director of the $\mathrm{Na}$ tional Humanities Alliance, an organization of which APSA is an active member.

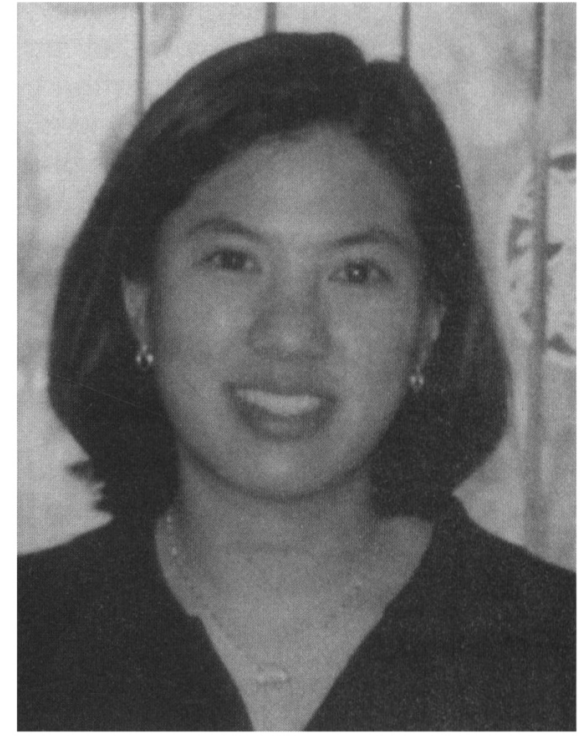

Melissa Chen

\section{APSA Congressional Fellowship Program Announces Winners}

APSA's 1997-98 class of Congressional Fellows will include 41 political scientists, journalists, Federal executives, and health policy professionals who participated in a nationwide and international competition for the Fellowships. It is the 45th class in program history.

The 1997-98 APSA Congressional Fellows are:

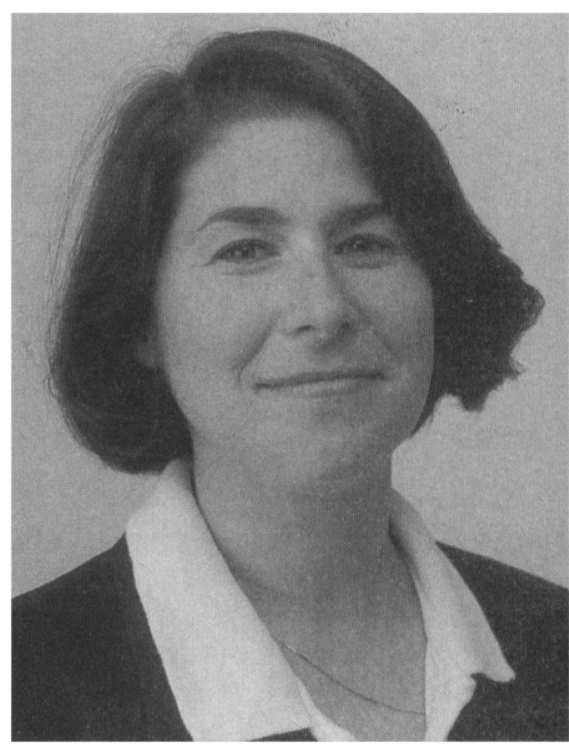

Diane Dwyre 